\title{
Algunas consideraciones sobre la función narrativa de las intervenciones autorales en Hero y Leandro de Museo: el caso de la sentencia
}

Daniel G. Gutiérrez

Universidad de Buenos Aires, Argentina

momolundpolo@gmail.com

Recibido: 16/09/2019. Aceptado: 20/11/2019.

\begin{abstract}
Resumen
Hero y Leandro es la única obra atribuida a Museo (siglo V d. C.). En este epilio tardoantiguo -o protobizantino-el autor presenta una trama formal compuesta por elementos épicos y novelescos, lo cual pone de manifiesto la naturaleza narrativa de la obra. Atendiendo al plano de la organización discursiva del material narrado, resulta significativo el hecho de que la voz del poeta intervenga en distintos momentos del relato, posicionándose como enunciador de sentencias o moralejas que contribuyen al desarrollo de la trágica historia de amor que se está narrando.
\end{abstract}

PALABRAS CLAVE: Hero y Leandro, intervención autoral, función discursiva, procedimientos narrativos, sentencia

Some considerations about the narrative function of the author's interventions in Hero and Leander of Musaeus: the case of the sentence

\begin{abstract}
Hero and Leander is the only work attributed to Musaeus (5th century AD). In this late-old or proto-Byzantine epyllion, the author presents a formal plot composed of epic and fictional elements, which highlights the narrative nature of the work. Taking into account the discourse organization of the narrated material, is significant the fact that the poet's voice intervenes at different moments of the story, positioning himself as an enunciator of sentences or morals that contribute to the development of the tragic love story he is narrating.
\end{abstract}

KEYWORDS: Hero and Leander, author intervention, discursive function, narrative procedures, sentence 
De Museo se sabe poco y nada. Probablemente fuera un erudito poeta imperial, al que se le otorgó el epíteto de grammatikós para distinguirlo del mitológico discípulo de Orfeo. ${ }^{1}$ Se conjetura que vivió en la segunda mitad del siglo V d. C., al parecer en Panópolis. Quizás haya profesado la fe cristiana. ${ }^{2}$ Se le atribuye la composición del epilio Hero y Leandro, ${ }^{3}$ que consta de 343 hexámetros.

En este poema hexamétrico Museo retoma la leyenda tradicional del trágico y tormentoso destino amoroso que afectó a los amantes de Sesto y de Abido. Desde el punto de vista estilístico, sigue los cánones compositivos y estructurales del epilio imperial, a la vez que toma ciertos elementos de la novela griega. ${ }^{4}$ Tan así es que para Dümmler (2012:434) el poema de Museo constituye una bisagra entre épica y novela, al que denomina 'hexameter novel'. Asimismo, Fernandes Simões (2006:100-126) argumenta, a partir de la teoría de los mythoi y de los géneros de Frye, que es posible inscribir el poema en la tradición novelesca griega. ${ }^{5}$

Este poema hexamétrico tardoantiguo -o protobizantino- presenta, entonces, una trama formal compuesta por elementos épicos y novelescos, lo cual pone de manifiesto su naturaleza narrativa. Teniendo en cuenta el plano del discurso, resulta significativo el hecho de que la voz del poeta intervenga en distintos momentos del relato, posicionándose como enunciador de conocimientos que contribuyen al desarrollo de la trágica historia de amor que está narrando.

El presente trabajo se propone dilucidar la función discursiva que cumplen dichas intervenciones autorales en la economía general del relato, prestando especial atención a los diversos procedimientos narrativos empleados para la consecución de tal fin.

Se puede comenzar preguntando por qué y con qué finalidad la voz del poeta interviene en distintos momentos del relato. Como hipótesis es factible sostener que el poeta, en tanto narrador, no interviene en los hechos narrados desde un posicionamiento estrictamente diegético, sino que además lo hace desde una posición situada por fuera del universo narrado. De este modo, promovería una vinculación entre el punto de vista inscrito en el texto y su

1 Según Cameron (1965), era de uso común atribuir el epíteto de ypaupatıкóc a los poetas egipcios del siglo IV-V d.C.; de entre los manuscritos más antiguos, el epíteto vpapuatıkós atribuido a Museo lo traen el ms. B (Bold. Bar. 50, s. X), el ms. V (Vat. gr. 915, s. XIII) y el ms. K (Paris. gr. 2600, s. XV), todos ellos de referencia según Livrea-Eleuteri (1982:i).

2 Keydell $(1933)$ y Gelzer $(1967,1968)$ sostienen que Museo era cristiano, mientras que Kost (1971) considera que no existe evidencia alguna de su fe religiosa. Para un breve panorama de esta debatida cuestión, puede con consultarse con provecho Fernandes Simões (2006:24-27).

3 Cantarella cuestiona el carácter de epyllion atribuido al poema: "es evidente que definir 'poemita' o 'epilion' a esta composición no es más que una convención. A pesar del lenguaje y el metro épico, y de las inevitables consecuencias estilísticas que ellos conllevan, no hay aquí nada de épico" (1972:350). Siguiendo la tradición manuscrita, el poema debería titularse Acerca de lo (referido) de Hero y Leandro (MOY $\mathrm{HP} \Omega \mathrm{KAI} \wedge \mathrm{EAN} \triangle \mathrm{PON}$ ), pues el título hace hincapié en una fórmula (artículo neutro plural + katá + acusativo) usada para referirse a lo ya narrado o contado, es decir, a lo que tiene carácter de leyenda; la fórmula, a su vez, con los nombres de los dos protagonistas, era usada para titular las novelas griegas desde el siglo I hasta el siglo V de nuestra era (cfr. Caritón de Afrodisias, Aquiles Tacio, Heliodoro, Longo, Jenofonte de Éfeso).

4 Según Villarubia, "la leyenda de Hero y Leandro es bastante antigua, pero no sería anterior al siglo III a.C." (2000:367). Entre los antecedentes directos del poema museístico se pueden mencionar: Verg. G. 3.258-263; Hor. Ep. I.3.3-4; Str. 13.1.22, 13.591; Ov. Ep. 18; 19; el fr. 951 del P. Ryland 3.486 (s. I. d.C.); Mela 1.9; 2.26; Sil. 8.619-621; Mart. 14.181; Sp. 25a; 25.b; Stat. Theb. 6.542-547; Fro. 3.13-14; Antip.Tess. (AP7.666), Antip. Mac. (APIX.215), el fr. 6 del P. Oxy. 6.864 (s. III d.C.) y el fr. 901 del P. Berol. 21249 (s. IV-V d.C.). Modelos de Museo habrían sido Calímaco, Aet. 3. fr. 67Pf.; fr. 80-83Pf.) y Nono de Panópolis (Dionisíacas); otros epilios imperiales fueron La toma de Ilión de Trifiodoro (de 691 versos) y El rapto de Helena de Coluto (de 394 versos). 
propia visión de los hechos narrados, induciendo una participación activa del oyente/lector que termina esbozando un nexo estrecho entre este y el contenido de la narración.

En el poema se pueden identificar un total de veinte intervenciones de la voz autoral. La frecuencia e identidad de Acto de Habla (AH) es el criterio que permite agruparlas de la siguiente manera: ${ }^{6}$

» sentencia (7 ocurrencias: vv. 37, 51-54, 92-93, 94-95, 131-132, 164-165,198-200).

» Comentario del narrador acerca de lo que acontece en el relato ( 3 ocurrencias: vv. 236, 287, 302).

» Opinión personal del narrador acerca de lo que acontece en el relato (3 ocurrencias: vv. 33, 66, 304-305).

» Interpelación diegética (dirigida a Leandro) (2 ocurrencias: vv. 86, 300ss.).

»Interpelación extradiegética (dirigida al oyente/lector) (2 ocurrencias: vv. 23, 59).

»Corrección enunciativa acerca de lo que acontece en el relato (1 ocurrencia: v. 64).

" Expresión de omnisciencia (1 ocurrencia: v. 291).

» Comentario de clausura (1 ocurrencia: v. 343).

En este trabajo sólo se dará cuenta del primer tipo de intervención autoral, es decir, de las intervenciones que valen como una sentencia. A continuación se reproduce cada uno de los pasajes del poema que vehiculizan esta intención comunicativa:

(1) v. 37 :

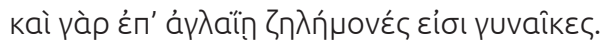

Pues también respecto de la belleza son celosas las mujeres. ${ }^{7}$

(2) vv. 51-54:

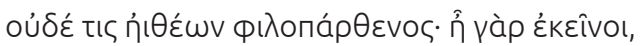

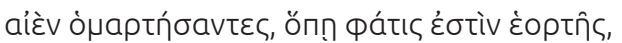

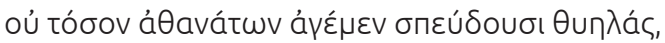

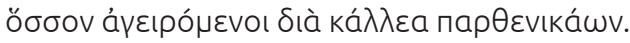

Ninguno de los donceles, amante de las vírgenes; pues en verdad estos,

siempre reunidos donde hay rumor de fiesta,

no se afanan tanto por llevar ofrendas a los inmortales,

cuanto por llevarlas, reuniéndose, debido a la belleza de las vírgenes.

(3) vv. 92-93:

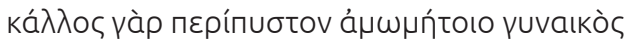

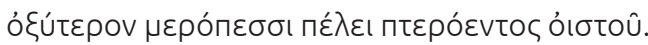

Pues la muy renombrada belleza de una mujer irreprochable es para los mortales más aguda que una alada flecha.

(4) vv. 94-95:

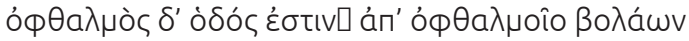

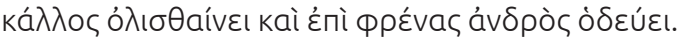

6 Se entiende por 'Acto de Habla' la acción que se realiza al decir algo, más allá del significado denotativo de la expresión (como, por ejemplo, aseverar, prometer, sugerir, etc.), cfr. Austin (1962). 
El ojo es el camino: desde los lances del ojo

la belleza se desliza y se encamina hasta los sentimientos del varón.

(5) vv. 198-200:

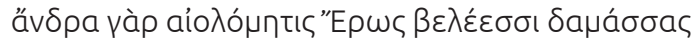

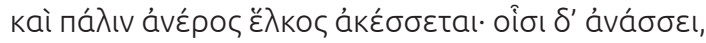

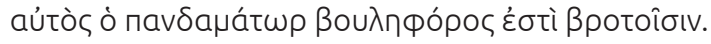

Pues Eros, astuto en ardides, tras sojuzgar a un varón con sus saetas, sanará de nuevo la herida de ese varón; y para los que gobierna, mortales, él mismo, el que a todos somete, es portador de consejos.

(5) vv. 131-132:

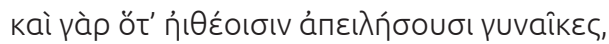

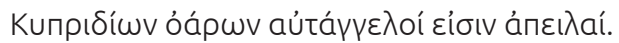

Pues incluso cuando las mujeres amenazan a los donceles,

las amenazas son anunciadoras mismas de las relaciones de Cípride.

(6) Vv. 164-165:

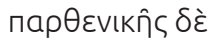

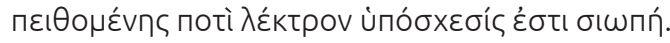

De virgen

convencida para el lecho, el silencio es promesa.

Es necesario aclarar que no se ofrecerá un estudio exhaustivo de todas y cada una de estas intervenciones autorales, pues el propósito principal del presente trabajo reside en dar cuenta del funcionamiento narrativo y discursivo que vehiculizan dichas intervenciones más que de su contenido concreto. Por esto mismo, se analizarán, a fines ilustrativos, solo dos de esas intervenciones autorales, quedando pendiente para futuros trabajos el análisis semántico / literario de las restantes intervenciones, así como el estudio de las otras intervenciones autorales consignadas.

En los casos listados la marca gramatical que permite identificar la intervención de la voz autoral es el cambio de tiempo verbal. Se pasa del uso de un tiempo pasado (que sería correlativo de exposición narrativa) al uso del presente (que sería correlativo de la sentencia). Es decir: el cambio en el plano gramatical se traduce en un cambio de Acto de Habla (AH). Véase, a modo de ejemplo, el entramado textual en el que aparece inserta la intervención autoral del verso 37:

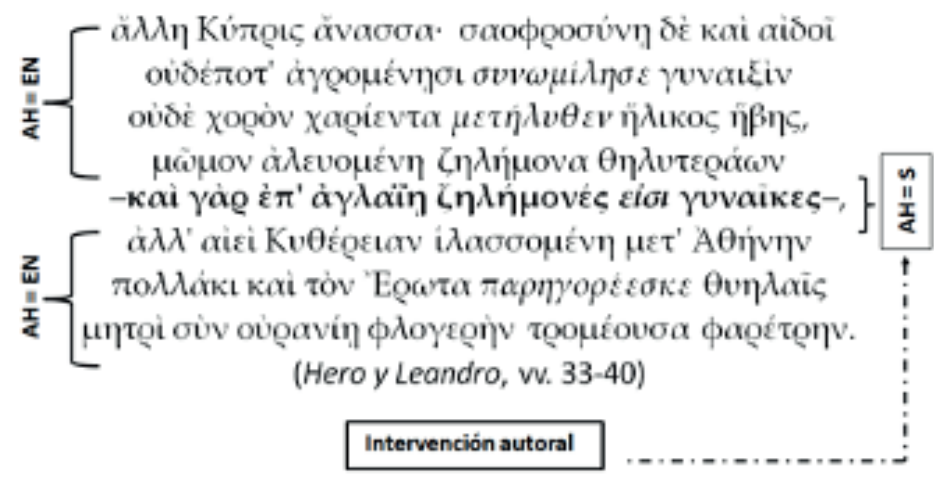


Nótese que en los versos 33-36 y en los versos 38-40 son usadas tres formas verbales conjugadas, dos en Aoristo (" $\sigma v v \omega \mu$ í $\lambda \eta \varepsilon \varepsilon$ ", v. 34, " $\mu \varepsilon \tau \eta \dot{\lambda} \lambda v \theta \varepsilon v$ ", v.

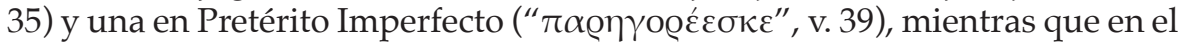
verso 37 la forma verbal está conjugada en Presente (" $\left.\varepsilon \grave{\imath} \iota^{\prime \prime}\right)$. Este cambio de tiempo verbal sería a su vez correlativo de un movimiento discursivo operante al interior de la superestructura narrativa.

T. van Dijk define las superestructuras discursivas como "estructuras globales que caracterizan el tipo de un texto" (1983:142) y las diferencia de las macroestructuras semánticas, que se vinculan con el 'significado global' de un texto, en tanto "reconstrucción teorética de nociones intuitivas tales como 'tema' o 'asunto' de un discurso" (1985:114). En este sentido, las superestructuras existen independientemente del contenido, siendo "una especie de esquema al que el texto se adapta" (1983:143). Una narración, por ejemplo, puede tratar sobre un hecho determinado (un robo), pero además de este tema global tiene la característica de que se trata de una 'narración'. El propio van Dijk (1983) indica que los textos narrativos son formas básicas globales de la comunicación que refieren ante todo a 'acciones' de personas que resultan tan 'interesantes' que deben ser relatadas. Estos rasgos, al convencionalizarse, dan lugar a distintas categorías (Complicación, Resolución, Episodio, etc.) que configuran toda superestructura narrativa, como puede observarse en el siguiente esquema: ${ }^{8}$

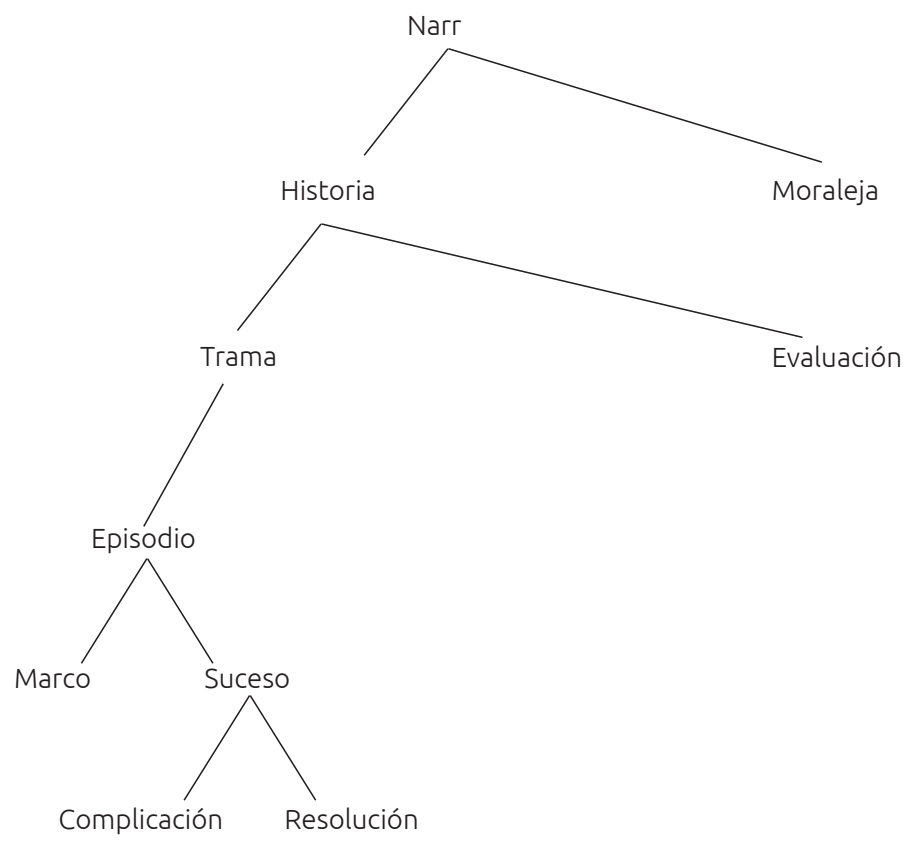

Aplicando este esquema al ejemplo anterior, y en función de lo previamente dicho, se puede vislumbrar cómo está funcionando el momento superestructural de la moraleja al interior de la narración que pone en juego Museo en Hero y Leandro: 


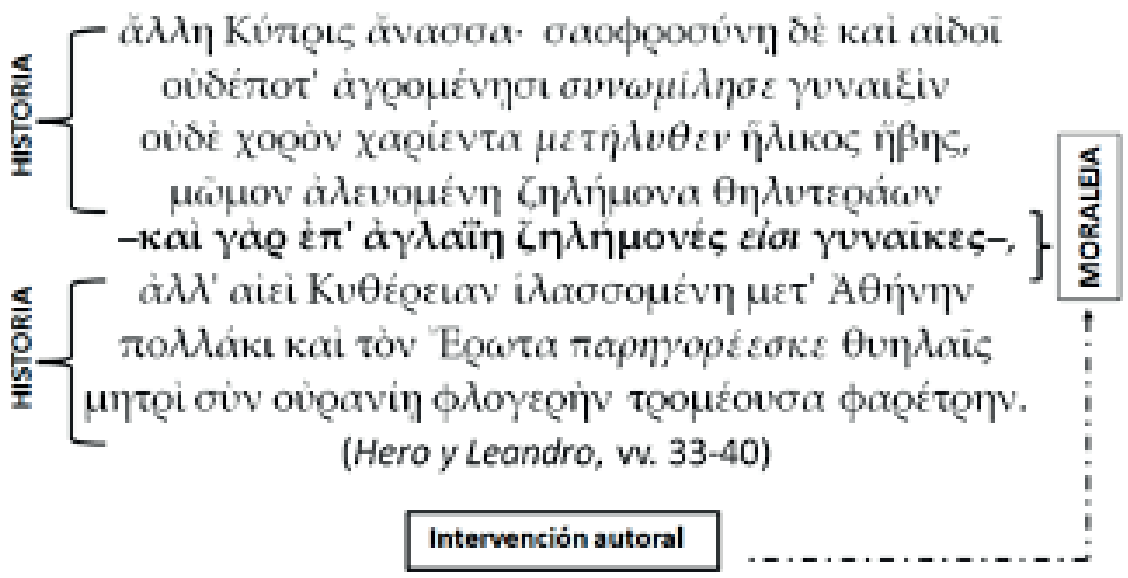

De este modo, las intervenciones de la voz autoral aquí consideradas, al suspender por unos instantes el flujo del discurso narrativo, estarían funcionando, dentro de la superestructura narrativa configurada en Hero y Leandro, como un saber práctico, esto es, como una sentencia o una moraleja destinada a la comprensión e interpretación del oyente/lector. En la cultura grecolatina la sentencia (o moraleja) posee los siguientes rasgos: (a) suelen ser construcciones breves, (b) vehiculizan un contenido moral, (c) el tiempo verbal tiende a ser el aoristo gnómico o el presente, (d) hacen referencia a temas generales como la condición humana, los rasgos femeninos, la fortuna amorosa, etc. ${ }^{9}$ Desde un enfoque pragmático del texto, van Dijk señala que en toda moraleja (o sentencia) se trata de ofrecer una "conclusión práctica" (1983:156) directamente vinculada con el devenir del relato en el que aparece inserta: “QQué se tendría/tendrá que hacer o no en el futuro si se tienen presentes los sucesos de la historia?" (1983:156).

Considérese ahora bajo esta luz la sentencia o moraleja del verso 37 (la que lleva el número (1) en el listado ofrecido más arriba):

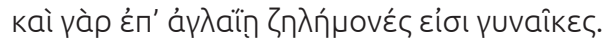

Pues también respecto de la belleza son celosas las mujeres.

En este pasaje la voz autoral pretende establecer un contraste entre $\gamma u v \eta ́$ (v. 34) y $\theta \tilde{\eta} \lambda u \varsigma$ (v. 36) con el propósito de resaltar el carácter animalizador del

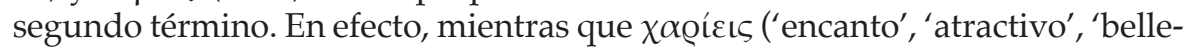
$\mathrm{za}^{\prime}, \mathrm{v} .35$ ) es un atributo que correspondería al universo de lo femenino, a la mujer en tanto constructo cultural que definiría la femineidad, $\zeta \eta \lambda \eta \mu \omega \nu$ ('ser celoso/a') sería, para Museo, un atributo que se correspondería con el sexo en sí, con la hembra, en tanto característica natural del sexo femenino. ${ }^{10} \mathrm{La}$

9 Görler (1963) ofrece una lista de funciones que serían propias de la sentencia (gnóme) en la cultura helénica, a saber: referencias de escena, de prólogo e informe de mensajero; expresiones gnómicas como introducción de un relato de escena; gnômai como inicio de monólogos con discurso de comentario; gnômai como inicio de un monólogo introductorio; gnômai como inicio de un discurso; gnômai de cierre; ideas gnómicas dentro de un relato. Como se hace evidente, las intervenciones autorales aquí consideradas se vinculan con esta última función.

10 Desde una perspectiva feminista "el género designa lo clasificado ('hombre' o 'mujer'), pero apela también y sobre todo al sistema general de identidad sexual que organiza tal clasificación con sus funciones normativas y prescriptivas. (...) el feminismo insiste en el carácter relacional de las identidades de género" 
palabra $\theta \tilde{\eta} \lambda u \varsigma$ ("hembra") opera, pues, en este pasaje designando lo opuesto a $\gamma v v \eta ́$, al responder a un esquema binario de connotación positiva / negativa: mujer (género, construcción cultural) vs. hembra (sexo, característica animal) respectivamente, con la adscripción de Hero a la primera categoría, lo que legitima su estatus como único y verdadero objeto de deseo de la historia que se está contando. ${ }^{11}$

Téngase en cuenta a continuación la sentencia o moraleja de los versos 94-95 (la que lleva el número (4) en el listado ofrecido más arriba):

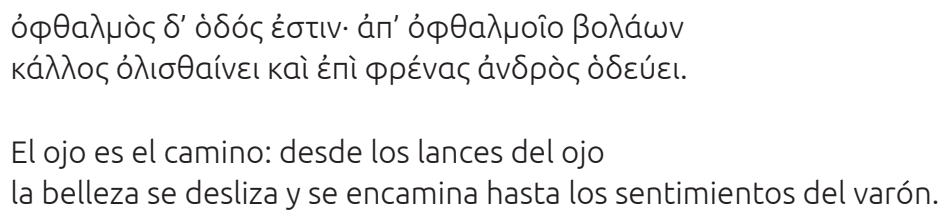

La voz autoral llama aquí la atención sobre la mirada como punto de partida y vía de acceso al éros, retomando el tópico del 'amor que entra por los ojos' o 'amor a primera vista', tópico que se remonta, por ejemplo, a Platón Phdr. 215b, 255c en su versión homoerótica y a Caritón de Afrodisias 1.1.6, Jenofonte de Éfeso 1.3.1-2 y Aquiles Tacio 1.4.4 en su versión heteroerótica. Este tópico parece ser funcional al relato, pues el texto construye un régimen 'escópico', un circuito de miradas entre ambos protagonistas (incluidas la del poeta y la del oyente / lector), que describe los caminos del deseo tanto de la mirada masculina como de la femenina, funcionado como marco del desenfreno erótico de Leandro que se narrará a continuación en el poema. Como señala Fernandes Simões, "o poeta desenvolve a imagística do olhar, concedendo-lhe um peso assinalável no âmbito da relação amorosa" (2006:34).

En función de estos dos ejemplos, se puede suponer que las intervenciones de la voz autoral en Hero y Leandro no solo conectan el punto de vista del lector/ oyente con el de los protagonistas, dotando de sentidos a la narración, sino que relacionan hechos dentro del mismo Episodio (entendido en términos superestructurales) a la vez que activan el conocimiento enciclopédico del lector/oyente como fuente de sentido del (su versión del) relato.

Estrechamente vinculado con lo anterior, las funciones de la sentencia o moraleja en la narración puesta en juego por Museo consistirían en presentar una matriz didáctica que, al entrelazarse con el relato, ofician como transmisoras de un saber necesario para dotar de significado a la diégesis. Ofrecen, asimismo, al oyente/lector el saber narrativo de un modo accesible y/o recuperable, lo que permite legitimar al narrador como testigo de una historia que conoce de antemano, involucrando al oyente/lector como agente indispensable para la comprensión de la historia que se está narrando.

En base a este funcionamiento narrativo de la sentencia o moraleja, la voz autoral en Hero y Leandro regularía (estratégicamente) el tempo de la narración con sus intervenciones. ${ }^{12}$ Según Eco, la regulación del tempo narrativo

(Richard, 2002:95).

11 Para un estudio más detallado de esta problemática, cfr. Gutiérrez (2017).

12 Dicha regulación del devenir del relato puede ser vinculada con la noción griega de kairós, entendida como el aprovechamiento estratégico de las ocasiones para la consecución de algún fin (cfr. Arist. EN1104a). Para un estudio detallado de la noción de kairós desde un punto de vista filosófico, se puede consultar Marramao (1992). 
constituye una estrategia autoral que permite al oyente/ lector realizar "paseos inferenciales":

Algunas de las técnicas de dilación o moderación del ritmo que el autor concretiza son las que deben permitir al lector paseos inferenciales. [...] Cuando hablaba de paseos inferenciales, me refería [...] a paseos imaginarios fuera del bosque [narrativo]: el lector para poder prever el desarrollo de la historia se remite a su experiencia de la vida, o a su experiencia de otras historias. [...] La actividad de previsión por parte del lector constituye un ineliminable aspecto pasional de la lectura, que pone en juego esperanzas y temores, y la tensión que se origina de la identificación con el destino de los personajes." (1996:60-61)

En el caso concreto de Hero y Leandro, el significado narrativo global del poema resultaría de un proceso cognitivo que organiza la experiencia en episodios temporalmente significativos (cfr. Goody, 1999), toda vez que la voz autoral haría hincapié en el tiempo de la memoria, de la focalización y de la recuperación de la experiencia (cfr. Ford, 1999). En este sentido, es posible pensar a Museo, en términos de lo que postula Walter Benjamin, como un auténtico narrador:

Un rasgo característico de muchos narradores natos es una orientación hacia lo práctico. [...] Todo ello indica la cualidad presente en toda verdadera narración. Aporta de por sí, velada o abiertamente, su utilidad; algunas veces en forma de moraleja, en otras, en forma de indicación práctica, o bien como proverbio o regla de vida. En todos los casos, el que narra es un hombre que tiene consejos para el que escucha [...]. El consejo no es tanto la respuesta a una cuestión como una propuesta ligada a la continuación de una historia en curso. [...] El consejo es sabiduría entretejida en los materiales de la vida vivida." (2001:114-115)

Con intervenciones como las aquí consideradas, Museo se configuraría al interior de su relato como poeta gnómico que revela su intención y capacidad de aplicar principios generales a una situación concreta dada, intuyendo las verdaderas motivaciones del otro. Como tal, no trata de especular en abstracto, sino de referir el saber práctico a diferentes casos, a la vez que expresa su saber motivado por los hechos que va narrando, todo lo cual implica un movimiento de lo particular a lo general. De esta manera, a Museo se le podría aplicar lo que postula Detienne (2004) respecto de la noción de 'maestro de la verdad', en tanto poeta que hace posible la emergencia de una alétheia secularizada.

En definitiva, con cada una de las sentencias presentes en Hero y Leandro el poeta panopolitano lograría establecer una equivalencia entre vida y narración, posibilitando así el ensanchamiento del campo de experiencias (prácticas, especulativas, vivenciales, etc.) del oyente/lector. 


\section{Bibliografía}

" Austin, J. (1962). How to do things with words. London: Oxford University Press.

» Ávila, A.; Bértola, J.; Gutiérrez, D.; Pedace M.L.; Velázquez, S. (s/F). Hero y Leandro de Museo, Traducción, estudio preliminar, notas y edición revisada del texto griego (en preparación).

» Benjamin, W. (2001). "El narrador". En: Para una crítica de la violencia y otros ensayos. Iluminaciones IV. Madrid: Taurus, 111-134.

"Cameron, A. (1965). "Wandering Poets: A Literary Movement in Byzantine Egypt", Historia 14, 491-497.

" Cantarella, R. (1972). La literatura griega de la época helenistica e imperial. Buenos Aires: Losada.

»Detienne, M. (2004). Los maestros de verdad en la Grecia arcaica. México: Sexto Piso.

" Dümmler, N. (2012). "Musaeus, Hero and Leander: Between Epic and Novel". En: Baumbach, M.; Bär, S. (eds.), Brill's Companion to Greek and Latin Epyllion and its Reception. Leiden: Brill, 411-446.

》Eco, U. (1996). Seis paseos por los bosques narrativos. Barcelona: Lumen.

» Fernandes Simões, M. (2006). A demanda do amor e o amor da demanda: Leituras de Hero e Leandro de Museu. Universidade de Lisboa, Facultade de Letras, Departamento de Estudos Clássicos: Tesis de Maestría en Estudios Clásicos - Literatura Griega.

» Ford, A. (1999). La marca de la bestia. Buenos Aires: Norma.

» Gelzer, Th., (1967). "Bemerkungen zu Sprache und Text des Epikers Musaios", MH24, 129-148.

» Gelzer, Th. (1968). "Bemerkungen zu Sprache und Text des Epikers Musaios", MH25, $11-47$.

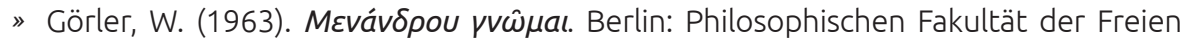
Universität.

" Goody, J. (1999). Representaciones y contradicciones. Barcelona: Paidós.

» Gutiérrez, D. (2017). "El otro rostro de la amada. Punto de vista masculino y construcción del personaje femenino en Hero y Leandro de Museo", Stylos 26, 106-124.

» Keydell, R. (1933). "Musaios", RE 16.1, 767-769.

» Kost, K. (1971). K., Mousaios. Hero und Leander. Einleitung, Text, Übersetzung und Kommentar. Bonn: Bouvier.

» Livrea, E. - Eleuteri, P. (1982). Musaeus. Hero et Leander. Leipzig: Teubner.

» Marramao, G. (1992). Kairós: Apología del tiempo oportuno. Barcelona: Gedisa.

» Richard, N. (2002). "Género”. En: Altamirano, C. (comp.). Términos críticos de sociología de la Cultura. Buenos Aires: Paidós, 95-101.

»Van Dijk, T. A. (1983). La ciencia del texto. Un enfoque interdisciplinario. Barcelona: Paidós.

"Van Dijk, T. A. (1985). "Semantic Discourse Analysis". En: van Dijk, T. A. (ed.), Handbook of discourse analysis - Dimensions of Discourse. Orlando: Florida, 103-136. 
"Villarrubia, A. (2000). "Notas sobre el poema Hero y Leandro de Museo", Habis 31, 365-401. 